\title{
Identificação de marcadores microssatélites relacionados ao escurecimento de grãos em feijão
}

\author{
Karla Rodrigues Couto(1), João Bosco dos Santos ${ }^{(1)}$, Magno Antônio Patto Ramalho(1) \\ e Graciele Simoneti da Silva(1)
}

\footnotetext{
(1)Universidade Federal de Lavras, Departamento de Biologia, Campus Universitário, CEP 37200-000 Lavras, MG. E-mail: karlarcouto@yahoo.com.br, jbsantos@dbi.ufla.br,magnoapr@ufla.br,g_simoneti@hotmail.com
}

Resumo - O objetivo deste trabalho foi identificar marcadores microssatélites ligados ao loco de características quantitativas (QTL) responsável pelo escurecimento tardio do tegumento de feijões do tipo carioca, a fim de reduzir o tempo de avaliação necessário para seleção quanto a essa característica. Foram utilizados dados de avaliação fenotípica de 185 progênies $\mathrm{F}_{2: 3}$ derivadas do cruzamento VC-3 x 'BRSMG Majestoso', para o estudo do controle genético do escurecimento dos grãos. Com esses dados, foram confeccionados dois "bulks" segregantes de DNA, empregados para a avaliação de 444 pares de primers SSR. Os aplicativos computacionais GQMOL e Sisvar foram utilizados para avaliar as segregações, confeccionar um grupo de ligação e realizar análises de marca simples e de regressão múltipla pelo método "backward". Oito marcadores apresentaram polimorfismo nos "bulks". Seis desses marcadores foram agrupados em um grupo de ligação de 80,49 cM, e destes, três mostraram-se estreitamente ligados ao QTL responsável pelo escurecimento tardio dos grãos. O marcador PVM02TC116 cossegregou com o QTL em questão, e os marcadores PVESTBR-98 (2,00 cM) e PV176 (12,24 cM) flanqueiam essa região, o que sugere elevada eficiência para possível uso na seleção assistida.

Termos para indexação: Phaseolus vulgaris, locos de características quantitativas, marcador molecular, seleção assistida, SSR.

\section{Identification of microsatellite markers associated with seed-coat darkening in common bean}

\begin{abstract}
The objective of this work was to indentify microsatellite markers linked to the quantitative trait loci (QTL) responsible for the late seed-coat darkening in the carioca type common bean, in order to reduce the evaluation time spent in selection for this trait. Data of seed-coat darkening of $185 \mathrm{~F}_{2: 3}$ progenies derived from the cross VC-3 x 'BRSMG Majestoso', were used. Out of these data, two segregating DNA bulks were constructed to evaluate 444 SSR primers. The applicatives GQMOL and Sisvar were used to evaluate the segregations, elaborate the linkage groups, and to perform single mark and regression analysis (backward method). Eight markers were polymorphic in the DNA bulks. Six of them were mapped in a 80.49-cM linkage group. Out of these six markers, three were very close to the QTL responsible for the late grain darkening. The PVM02TC116 marker co-segregate with that QTL, and the PVESTBR-98 (2.00 cM) and PV176 (12.24 cM) ones flank it, which indicates that high efficiency in the assisted selection is possible.
\end{abstract}

Index terms: Phaseolus vulgaris, quantitative trait loci, molecular marker, assisted selection, SSR.

\section{Introdução}

O feijão é um dos mais importantes componentes da dieta alimentar do brasileiro, com um consumo per capita superior a $17 \mathrm{~kg} \mathrm{ano}^{-1}$ (Brasil, 2010). É reconhecidamente uma excelente fonte proteica, contém grandes quantidades de carboidratos complexos, fibras e compostos fenólicos com ação antioxidante, que podem reduzir a incidência de doenças (Anderson et al., 1999). O feijão do tipo carioca é o mais produzido no país, com $63 \%$ do total da produção nacional (Brasil, 2010).
Entre os diversos caracteres que afetam a aceitação de cultivares do feijão tipo carioca pelos produtores, o escurecimento precoce do tegumento do feijão é um dos mais importantes, devido à associação, por parte dos consumidores, da cor escura do grão com a dificuldade de cozimento, o que causa uma grande depreciação no valor comercial (Sartori, 1996).

O escurecimento do feijão no armazenamento está relacionado com a suscetibilidade da cultivar (Burr et al., 1968) e com as condições ambientais. O escurecimento do tegumento geralmente está relacionado à alta umidade e temperatura, e a longos 
períodos de armazenamento (Burr et al., 1968; Sartori, 1982; Iaderoza et al., 1989).

O melhoramento de cultivares de feijão com tipo carioca tem-se concentrado em grãos com o fundo mais claro possível e, também, na manutenção da cor clara pelo maior tempo possível (Silva et al., 2008). Segundo esses autores, a avaliação do escurecimento do grão requer, pelo menos, de dois a três meses após a colheita, e a segregação para escurecimento de grãos se ajusta à proporção de 3 escuros : 1 claro, indicativo de que o caráter é controlado por um único gene com dominância para o alelo de escurecimento precoce. Resultado semelhante foi obtido por Junk-Knievel et al. (2008).

Assim, em razão de ser simples o controle genético do caráter, há maior possibilidade de se identificar marcadores moleculares para o alelo ou QTL responsável pelo fenótipo ideal. A identificação de marcadores associados ao alelo responsável pelo retardamento do escurecimento dos grãos possibilitaria a utilização da seleção assistida por marcadores para esse caráter, o que a tornaria muito mais rápida.

O objetivo do presente trabalho foi identificar marcadores microssatélites ligados a alelos responsáveis pelo escurecimento tardio do tegumento de feijões do tipo carioca.

\section{Material e Métodos}

Foram utilizadas 185 progênies $F_{2: 3}$, provenientes do cruzamento entre a linhagem VC-3, oriunda do programa de melhoramento da Universidade Federal de Viçosa, e a cultivar BRSMG Majestoso - denominada neste trabalho apenas de Majestoso -, indicada para semeadura no Estado de Minas Gerais, e obtida pela Universidade Federal de Lavras em parceria com a Universidade Federal de Viçosa, Epamig e Embrapa Arroz e Feijão.

A linhagem VC-3 apresenta grão do tipo carioca com fundo creme bem claro, e há evidências de que essa tonalidade persiste por longo período. Já a cultivar Majestoso também possui padrão de grão tipo carioca com fundo claro, porém, escurece rapidamente com o armazenamento (Silva et al., 2008).

Cada progênie $\mathrm{F}_{2: 3}$ foi avaliada individualmente quanto ao escurecimento dos grãos. Para isso, os grãos de cada planta $\mathrm{F}_{2}$ foram colocados em uma embalagem de plástico transparente com $5 \mathrm{~cm}$ de diâmetro e $21 \mathrm{~cm}$ de comprimento. Aos 30, 60 e 90 dias após a colheita, foi avaliado o escurecimento de grãos por meio da escala de notas proposta por Silva et al. (2008): 1, cor de fundo do grão muito clara; 2, medianamente clara; 3, clara; 4, medianamente escura; 5, muito escura. As notas foram atribuídas por dois avaliadores, isoladamente, tendo-se considerado a média desses avaliadores. Foram utilizadas as notas dadas aos 60 dias de armazenamento, já que, segundo Silva et al. (2008), essa é a melhor época para avaliação dessa característica.

Uma amostra de 16 sementes de cada uma das 185 progênies foi semeada em bandejas de isopor de 96 células, preenchidas com substrato, mantidas em casa de vegetação com irrigação controlada. Quinze dias após a semeadura, foi coletada uma folha jovem de cada planta e extraído o DNA de cada progênie, tendose utilizado o protocolo empregado por Pereira et al. (2008). A concentração do DNA genômico foi estimada em eletroforese em gel de agarose a $1 \%$, tendo-se utilizado $5 \mu \mathrm{L}$ de "low DNA mass ladder" (Invitrogen Corporation, Carlsbad, EUA) como padrão. Alíquotas das diferentes concentrações de DNA foram usadas para padronizar o estoque de uso, para todos os genótipos, a $10 \mathrm{ng} \mu \mathrm{L}^{-1}$, com diluição em água pura. O DNA de cada progênie foi acondicionado em geladeira a $4^{\circ} \mathrm{C}$, para posterior uso nas reações de microssatélites (SSR).

Os dados da avaliação fenotípica realizada por Silva et al. (2008) foram analisados e, a partir deles, progênies com notas inferiores a 2,5 foram consideradas claras, e com notas superiores ou iguais a 2,5, escuras. Desse modo, para se identificar o polimorfismo relacionado ao escurecimento tardio dos grãos, foram selecionadas 13 progênies avaliadas como portadoras de grãos escuros e 13 progênies, como portadoras de grãos claros, para confecção de dois "bulks" contrastantes, de acordo com a metodologia proposta por Michelmore et al. (1991). Quantidades equimolares de DNA das 13 progênies com grãos escuros e das 13 progênies com grãos claros foram utilizadas para a montagem dos "bulks" contrastantes, e foram avaliados também dois indivíduos considerados de grãos escuros e dois de grãos claros, para auxiliar na identificação de híbridos dentro dos respectivos "bulks".

Foram testados 444 pares de primers SSR, específicos para feijoeiro, disponíveis no LGMol. Os marcadores identificados como polimórficos foram avaliados nas 185 progênies $F_{2: 3}$. $O$ procedimento 
utilizado para se realizar a reação microssatélite foi o mesmo empregado por Pereira et al. (2008). Os produtos amplificados foram separados por eletroforese, em gel de poliacrilamida a $6 \%$ não desnaturante, e corados com nitrato de prata de acordo com protocolo de Creste et al. (2001).

A segregação dos marcadores foi avaliada com o auxilio do programa GQMOL versão 2006.9.1 (Cruz \& Schuster, 2004), com aplicação do teste estatístico qui-quadrado $\left(\chi^{2}\right)$ para testar a hipótese de segregação esperada (1:2:1), prevista para um marcador codominante em uma população $\mathrm{F}_{2}$. Um mapa genético de ligação, baseado nos dados da $\mathrm{F}_{2}$ para os marcadores microssatélites polimórficos, foi construído com uso do programa GQMOL. Os critérios utilizados foram um valor mínimo de escore limite de detecção (LOD) de 3,0 e frequência máxima de recombinação de $30 \%$. As frequências de recombinação foram corrigidas com base na função de distância de mapa de Kosambi. A identificação de QTL foi realizada com o uso do mapa molecular e das informações fenotípicas. Como critério para as informações fenotípicas, as progênies com notas inferiores a 2,5 foram consideradas claras, e as com notas superiores ou iguais a 2,5 foram consideradas escuras.

Ainda com uso do aplicativo GQMOL, foram realizadas análises de QTL para marcas simples, de modo a associar as notas médias de tegumento claro ou escuro com cada banda SSR. Também foram realizadas análises de regressão múltipla utilizando-se o método "backward" (Draper \& Smith, 1998), com o auxílio do aplicativo computacional Sisvar 5.3 (Ferreira, 2008).

\section{Resultados e Discussão}

Dos 444 pares de primers testados, somente 13 apresentaram polimorfismo, e apenas oito possibilitaram a diferenciação entre os "bulks": PV35, PV67, PV59, PV176, PVEST-6, PVEST-98, X57022, PVM02TC116 (Tabela 1). O baixo polimorfismo encontrado entre os locos avaliados pode estar relacionado à estreita base genética, já que os genitores do cruzamento são linhagens elites do mesmo centro de domesticação (Mesoamericano) e, principalmente, do mesmo tipo comercial (carioca), desenvolvidos no Estado de Minas Gerais.

Obaixo número de marcadores tem sido um problema para construção de mapas em várias espécies com base genética estreita (Fatokun et al., 1992; Menéndez et al., 1997). Em feijão, esse problema é comum e tem sido relatado em diversos trabalhos, mesmo quando se utilizam genitores bastante contrastantes (Faleiro et al., 2003; Teixeira et al., 2005; Blair et al., 2006). Alguns trabalhos recentes, realizados com populações obtidas a partir de linhagens elites derivadas de programas de melhoramento, têm mostrado polimorfismo ainda menor (Faleiro et al., 2003; Teixeira et al., 2005; Blair et al., 2006; Pereira et al., 2007, 2008; Torga et al., 2010).

Os testes de $\chi^{2}$ para os oito marcadores foram altamente significativos, o que indica que os marcadores apresentaram segregação distorcida em relação à esperada (Tabela 2). Vale salientar que a população utilizada possuía 185 progênies $\mathrm{F}_{2: 3}$, um

Tabela 1. Sequências de nucleotídeos dos oito marcadores polimórficos, e temperaturas de anelamento utilizadas ${ }^{(1)}$.

\begin{tabular}{|c|c|c|}
\hline Marcador & Sequência 5'-3' & Anelamento $\left({ }^{\circ} \mathrm{C}\right)$ \\
\hline \multirow{2}{*}{ PV35 } & TCTACGCGTTCCCTCTGTCT & \multirow{2}{*}{$62-62$} \\
\hline & AGTGGATGTGTGGGAAAAGC & \\
\hline \multirow{2}{*}{ PV67 } & TGAGCCATATATTTTTTCTCACTCTT & \multirow{2}{*}{$58-58$} \\
\hline & ATGGGCATGGTGGATGATTAG & \\
\hline \multirow{2}{*}{ PV59 } & TTGAGTGAGCCCATATATTTTTCTC & \multirow{2}{*}{$58-58$} \\
\hline & GTTGGTGTGGGAAGAGAGGA & \\
\hline \multirow{2}{*}{ PV176 } & GAGGAAAGAGAAAGCAACAGAGA & \multirow{2}{*}{$55-55$} \\
\hline & AGTTTGAGGAGCAGGAGCAG & \\
\hline \multirow{2}{*}{ PVESTBR-6 } & TTTTGAGGATTGGGAATATTGG & \multirow{2}{*}{$58-58$} \\
\hline & TCAAATGGACTCACGATTAACTTGC & \\
\hline \multirow{2}{*}{ PVESTBR-98 } & TCTTTAACAGCGCACACACTTT & \multirow{2}{*}{$58-58$} \\
\hline & GTTGGAAAACGACAGTAGGAACC & \\
\hline \multirow{2}{*}{ X57022 } & AAGGATGGGTTCCGTGCTTG & \multirow{2}{*}{$58-58$} \\
\hline & CACGGTACACGAAACCATGCTATC & \\
\hline
\end{tabular}

(1)Bean Improvement Crop (2010).

Tabela 2. Teste $\chi^{2}$ da segregação fenotípica da geração $\mathrm{F}_{2}$, para os oito marcadores microssatélites polimórficos.

\begin{tabular}{|c|c|c|c|c|c|}
\hline \multirow[t]{2}{*}{ Marcador } & \multicolumn{3}{|c|}{ Proporções $^{(1)}$} & \multirow[t]{2}{*}{ Segregação } & \multirow[t]{2}{*}{$x^{2}$} \\
\hline & $\mathrm{A}_{\mathrm{i}}^{1} \mathrm{~A}_{\mathrm{i}}^{1}$ & $\mathrm{~A}_{\mathrm{i}}^{1} \mathrm{~A}_{\mathrm{i}}^{2}$ & $\mathrm{~A}_{\mathrm{i}}^{2} \mathrm{~A}_{\mathrm{i}}^{2}$ & & \\
\hline PV35 & 67 & 27 & 91 & $1: 2: 1$ & $98,98 * *$ \\
\hline PV67 & 56 & 55 & 74 & $1: 2: 1$ & $33,90 * *$ \\
\hline PV59 & 60 & 59 & 66 & $1: 2: 1$ & $24,65^{* *}$ \\
\hline PV176 & 50 & 35 & 100 & $1: 2: 1$ & $98,51 * *$ \\
\hline PVESTBR-6 & 64 & 6 & 58 & $1: 2: 1$ & $105,69 * *$ \\
\hline PVESTBR-98 & 63 & 72 & 50 & $1: 2: 1$ & $10,91 * *$ \\
\hline X57022 & 67 & 44 & 73 & $1: 2: 1$ & $50,48^{* *}$ \\
\hline PVM02 TC166 & 70 & 68 & 47 & $1: 2: 1$ & $18,70^{* *}$ \\
\hline
\end{tabular}

${ }^{(1)} A_{i}^{1} A_{i}^{1}$, proporção observada do homozigoto para o alelo $A_{i}^{1}$ para o iésimo marcador; $A_{i}^{1} A_{i}^{2}$, proporção observada de heterozigotos do iésimo marcador; e $A_{i}^{2} A_{i}^{2}$, proporção observada do homozigoto para o alelo $A_{i}^{2}$ para o iésimo marcador. **Significativo a $1 \%$ de probabilidade. 
tamanho mais do que suficiente para evitar a distorção de segregação pelo acaso. Segundo Xu (2008), se os marcadores apresentam distorção de segregação, eles estão associados a genes para a viabilidade, nos quais ocorre seleção gamética ou zigótica. Evidências mostram que marcadores com desvio de segregação não se agrupam aleatoriamente nos mapas de ligação (Thoquet et al., 2002).

Não são conhecidos trabalhos na literatura sobre identificação molecular de genes relacionados ao escurecimento de grãos em feijão. Entretanto, se marcadores com distorção de segregação são usados no mapeamento de QTLs e a distorção é ignorada, a eficiência em se detectar o QTL é levemente reduzida. Se o mapa é denso, essa perda de eficiência pode ser considerada desprezível. Ainda, se o marcador cossegrega com o QTL, este é completamente determinado pelo marcador, e a distorção é irrelevante (Xu, 2008).

Harushima et al. (1996) e Lyttle (1991) relataram que o desvio da proporção de segregação mendeliana esperada tem sido observado em progênies de cruzamentos intra e interespecíficos, e a causa desses desvios se encontra em fatores de distorção da segregação que afetam a competição entre os gametas ou que causam a falha do gameta ou do zigoto. Altos graus de desvios foram encontrados em vários cruzamentos, intra e interespecíficos, com o gênero Citrus, independentemente da espécie e do tipo de marcador utilizado (Oliveira et al., 2004). Tanksley et al. (1992) sugeriram que rearranjos cromossômicos e seleção gamética, zigótica ou pós-zigótica podem causar desvios de segregação em várias espécies. Segundo Ruiz \& Asins (2003), a presença de fatores letais recessivos e o favorecimento de alguns alelos na seleção gamética, por exemplo, são possíveis causadores de segregação distorcida em citros, em nível gamético, ou zigótico, no caso do aborto do embrião.

Com base em dados dos marcadores polimórficos, um grupo de ligação de 80,49 cM foi obtido, no qual seis dos oito marcadores polimórficos foram agrupados de acordo com os parâmetros estabelecidos pelo aplicativo GQMOL (Figura 1).

O marcador PVM02TC116 apresentou frequê ncia de recombinação igual a zero, o que i ndica que ele cossegrega com o QTL em questão. Outros dois marcadores, X57022 e PVESTBR-98, apresentaram distância de 2,00 cM. Esses três marcadores, por apresentarem frequência de recombinação muito baixa, podem oferecer grande auxílio na realização de seleção assistida contra o escurecimento precoce dos grãos. Esse resultado é extremamente relevante, pois pode diminuir o tempo de avaliação dessa característica, uma vez que a planta portadora do marcador e do

Distância (cM) Marcadores

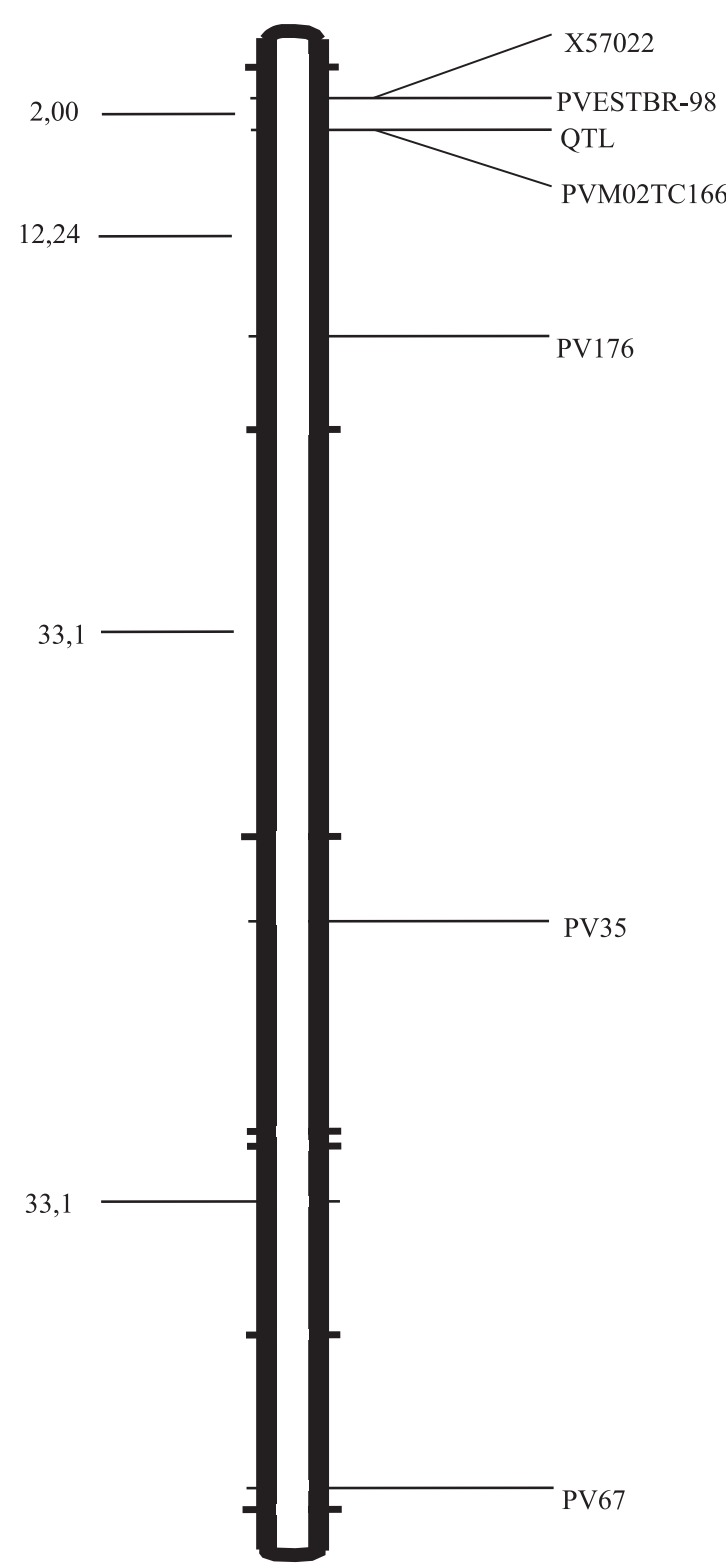

Figura 1. Grupo de ligação com o melhor ordenamento e as distâncias estimadas pela função Kosambi, entre os seis marcadores ligados e o QTL responsável pelo retardamento do escurecimento dos grãos em feijão carioca. 
QTL de interesse pode ser identificada logo após a germinação.

Os outros três marcadores polimórficos - PV176, PV35 e PV67 -, apesar de mais distantes, com $12,24,33,10$ e 33,10 cM, respectivamente, também foram integrados ao grupo. Embora distantes, esses marcadores podem ser úteis em futuras pesquisas que visem à saturação do mapa de ligação do feijoeiro. Já os marcadores PV59 e PVEST-6 não foram agrupados por estarem a mais de $50 \mathrm{cM}$ dos outros, ou seja, não ligados e, portanto, inúteis para auxiliar na seleção indireta.

É inquestionável que PVM02TC116 é o marcador ideal para a seleção assistida. Apesar de ter apresentado desvio de segregação, seu $\chi^{2}$ está entre os menores. Aliado a isso, a frequência de recombinação zero indica que um alelo do marcador sempre ocorreu no genótipo com QTL para grão claro e o outro alelo no genótipo com QTL para grão escuro, o que assegura a sua utilidade, conforme Xu (2008).

Os dois marcadores situados a 2,00 cM, juntamente com o PV176, estão flanqueando o QTL de interesse, e o uso deles também pode propiciar grande eficiência da seleção assistida (Figura 1). Por exemplo, o uso do PVESTBR-98 e o PV176, simultaneamente, implica ocorrência de permuta dupla de apenas $0,12 \%$, quanto se admite ausência de interferência para se selecionar a planta com os dois marcadores sem o QTL de interesse (Ramalho et al., 2008). Como os marcadores microssatélites são do tipo codominante, pode-se selecionar as plantas homozigóticas para os dois marcadores, e a seleção assistida, nesse caso, terá eficiência próxima de $100 \%$.
Nas análises de variância por marca simples, foi identificado que os três primeiros marcadores relacionados na Tabela 3 explicam as variações no escurecimento do grão, com destaque para os marcadores PVESTBR-98 e PVM02TC116, que explicaram, individualmente, as maiores percentagens da variação. Ao se observar as médias de escurecimento de grãos dos três genótipos de cada um dos marcadores, nota-se que os três primeiros são os mais úteis para seleção assistida, pois possuem médias diferentes em cada genótipo, além de ser possível identificar o alelo de cada marcador que está associado ao fenótipo ideal para escurecimento tardio.

O marcador X57022, mapeado a 2,00 cM do QTL, não explicou nenhuma variação para o escurecimento dos grãos, visto que as médias dos três genótipos para esse marcador foram praticamente iguais. O mapeamento desse marcador a 2,00 cM do QTL pode ocorrer devido ao forte desvio de segregação observado para ele. Assim, com a disponibilidade de outros marcadores mais eficientes, o uso desse marcador na seleção assistida não é recomendado.

Os resultados obtidos pela regressão múltipla e pelo método de seleção do modelo "backward" (Ferreira, 2008) foram concordantes com o mapeamento gerado por meio do GQMOL, exceto quanto ao marcador X57022, que não foi considerado. Isso ocorreu provavelmente em razão do procedimento de análise: os dois marcadores, X57022 e PVESTBR-98, foram considerados variáveis multicolineares, isto é, por serem mapeadas muito próximas, são correlacionadas, e apenas uma é suficiente para participar do modelo (Draper \& Smith, 1998). O coeficiente de determinação do modelo de regressão ajustado foi

Tabela 3. Resumo das análises de marcas simples para as notas de escurecimento de grãos, para cada um dos marcadores.

\begin{tabular}{|c|c|c|c|c|c|c|c|c|}
\hline \multirow[t]{2}{*}{ Marcador } & \multirow[t]{2}{*}{ GL } & \multirow[t]{2}{*}{$\mathrm{QM}$} & \multirow[t]{2}{*}{$\mathrm{F}$} & \multirow[t]{2}{*}{$\mathrm{P}$} & \multirow[t]{2}{*}{$\mathrm{R}^{2}$} & \multicolumn{3}{|c|}{ Médias $^{(1)}$} \\
\hline & & & & & & $\mathrm{A}_{\mathrm{i}}^{1} \mathrm{~A}_{\mathrm{i}}^{1}$ & $\mathrm{~A}_{\mathrm{i}}^{1} \mathrm{~A}_{\mathrm{i}}^{2}$ & $\mathrm{~A}_{\mathrm{i}}^{2} \mathrm{~A}_{\mathrm{i}}^{2}$ \\
\hline PV176 & 2 & 13,55 & 15,71 & 0,00 & 0,1465 & 4,01 & 3,53 & 3,17 \\
\hline PVM02TC116 & 2 & 34,69 & 55,01 & 0,00 & 0,3755 & 4,29 & 3,68 & 2,84 \\
\hline PVESTBR-98 & 2 & 41,70 & 75,32 & 0,00 & 0,4515 & 4,31 & 3,65 & 2,70 \\
\hline PV35 & 2 & 0,19 & 0,18 & 1,00 & 0,0020 & 3,59 & 3,46 & 3,52 \\
\hline PV59 & 2 & 2,13 & 1,97 & 0,14 & 0,0211 & 3,66 & 3,13 & 3.32 \\
\hline PVESTBR-6 & 2 & 0,29 & 0,29 & 1,00 & 0,0032 & 3,54 & 3,47 & 3,60 \\
\hline X57022 & 2 & 0,03 & 0,03 & 1,00 & 0,0003 & 3,51 & 3,56 & 3,52 \\
\hline PV67 & 2 & 1,02 & 1,02 & 0,36 & 0,0110 & 3,44 & 3,67 & 3,47 \\
\hline
\end{tabular}

${ }^{(1)} \mathrm{A}_{\mathrm{i}}^{1} \mathrm{~A}_{\mathrm{i}}^{1}$, médias de escurecimento do homozigoto para o alelo $\mathrm{A}_{\mathrm{i}}^{1}$ para o iésimo marcador; $\mathrm{A}_{\mathrm{i}}^{1} \mathrm{~A}_{\mathrm{i}}^{2}$, médias de escurecimento dos heterozigotos do iésimo marcador; e $A_{i}^{2} A_{i}^{2}$, médias de escurecimento do homozigoto para o alelo $A_{i}^{2}$ para o iésimo marcador . 
Tabela 4. Análise de variância pelo método de regressão múltipla com seleção de modelo pelo método backward, para os marcadores PVM02TC166, PVESTBR-98, PV176.

\begin{tabular}{lcrrrr}
\hline Fonte de variação & GL & \multicolumn{1}{c}{ SQ } & QM & Fc & Pr $>$ Fc \\
\hline Modelo & 3 & 77,85 & 25,95 & 44,18 & 0.000 \\
Erro & 181 & 106,30 & 0,58 & & \\
Total corrigido & 184 & 184,16 & & & \\
Total não corrigido & 184 & 2487,31 & & & \\
\hline Raiz do QME & 0,76 & \\
\hline $\mathrm{R}^{2}$ & 0,42 & \\
\hline $\mathrm{R}^{2}$ ajustado & \multicolumn{5}{c}{3,41} \\
\hline Média & 3,52 \\
\hline $\mathrm{CV}(\%)$ & 21,72 \\
\hline
\end{tabular}

de $41,2 \%$ e corresponde à percentagem da variação da cor do grão explicada pelos três marcadores PVESTBR-98, PVM02TC116 e PV176 (Tabela 4). Esse coeficiente de determinação foi menor do que o esperado, certamente porque na avaliação fenotípica ocorreram desvios não explicados pelos marcadores, provavelmente originados do procedimento dessa avaliação fenotípica. Além disso, as distorções de segregação podem ter contribuído para a redução do coeficiente de determinação (Xu, 2008).

Os marcadores PVESTBR-98 e PV176 não foram eliminados na análise de regressão e, por isso, foram feitas análises de segregação destes com o marcador PVM02TC116 separadamente. A segregação observada em ambos os casos foi de 1:2:1:2:4:2:1:2:1, que confirma a existência de apenas um QTL.

\section{Conclusões}

1. O marcador PVM02TC116 cossegrega com o QTL que controla o escurecimento de grãos em feijão-carioca, e seu uso é promissor para a seleção assistida por marcadores.

2. Os marcadores PV176 e PVESTBR-98 flanqueiam o QTL que controla o escurecimento de grãos em feijão-carioca, e podem também ser utilizados para a seleção assistida por marcadores.

\section{Referências}

ANDERSON, J.W.; SMITH, B.M.; WASHNOCK, C.S. Cardiovascular and renal benefits of dry bean and soybean intake. American Journal of Clinical Nutrition, v.70, p.464-474, 1999.

BEAN IMPROVEMENT COOPERATIVE. Bean Improvement Cooperative [home page]. Disponível em: <http:/www.css.msu. edu/bic/>. Acesso em: 15 jan. 2010.
BLAIR, M.W.; GIRALDO, M.C.; BUENDÍA, H.F.; TOVAR, E.; DUQUE, M.C.; BEEBE, S.E. Microsatellite marker diversity in common bean (Phaseolus vulgaris L.). Theoretical and Applied Genetics, v.113, p.100-109, 2006.

BRASIL. Ministério da Agricultura, Pecuária e Abastecimento. Companhia Nacional de Abastecimento [home page]. 2010. Disponível em: <http://www.conab.gov.br/conabweb>. Acesso em: 10 jan. 2010.

BURR, H.K.; KON, S.; MORRIS, H.J. Cooking rates of dry beans as influenced by moisture content, temperature and time of storage. Food Technology, v.22, p.336-338, 1968.

CRESTE, S.; TULMANN NETO, A.; FIGUEIRA, A. Detection of single sequence repeat polymorphisms in denaturing polyacrylamide sequencing gels by silver staining. Plant Molecular Biology Reporter, v.19, p.299-306, 2001.

CRUZ, C.D.; SCHUSTER, I. GQMOL: genética quantitativa e molecular. Viçosa: UFV, 2004.

DRAPER, N.R.; SMITH, H. Applied regression analysis. 3.ed. New York: J. Wiley \& Sons, 1998.

FALEIRO, F.G.; SCHUSTER, I.; RAGAGNIN, V.A.; CRUZ, C.D.; CORRÊA, R.X.; MOREIRA, M.A.; BARROS, E.G. de. Caracterização de linhagens endogâmicas recombinantes e mapeamento de locos de características quantitativas associados a ciclo e produtividade do feijoeiro comum. Pesquisa Agropecuária Brasileira, v.38, p.1387-1397, 2003.

FATOKUN, C.A.; DANESH, D.; MENANCIO-HAUTEA, D.I.; YOUNG, N.D. A linkage map for cowpea [Vigna unguiculata (L.) Walp] based on DNA markers $(2 \mathrm{~N}=22)$. In: O'BRIEN, J.S. (Ed.).

Genetic maps: a compilation of linkage and restriction maps of genetically studied organisms. Cold Spring Harbor: Cold Spring Harbor Laboratory, 1992. p.6256-6258.

FERREIRA, D.F. SISVAR: um programa para análises estatísticas e ensino de estatística. Revista Symposium, v.6, p.36-41, 2008.

HARUSHIMA,Y; KURATA, N.; YANO, M.; NAGAMURA, Y.; SASAKI, T.; MINOBE, Y.; NAKAGAHRA, Y. Detection of segregation distortions in an indica-japonica rice cross using a high-resolution molecular map. Theoretical and Applied Genetics, v.92, p.145-150, 1996.

IADEROZA, M.; SALES, A.M.; BALDINI, V.L.S.; SARTORI, M.R.; FERREIRA, V.L.P. Polyphenol oxidase activity and alterations in colour and levels of condensend tannins during storage of new bean (Phaseolus) cultivars. Coletânea do Instituto de Tecnologia de Alimentos, v.19, p.154-164, 1989.

JUNK-KNIEVEL, D.C.; VANDERBERG, A.; BETT, K.E. Slow darkening in pinto bean (Phaseolus vulgaris L.) seed coats is controlled by a single major gene. Crop Science, v.48, p.189-193, 2008.

LYTTLE, T.W. Segregation distorters. Annual Review of Genetics, v.25, p.511-557, 1991.

MENÉNDEZ, C.M.; HALL, A.E.; GEPTS, P. A genetic linkage maps of cowpea (Vigna unguiculata) developed from a cross between two inbred, domesticated lines. Theoretical and Applied Genetics, v.95, p.1210-1217, 1997. 
MICHELMORE, R.W.; PARAN, I.; KESSELI, R.V. Identification of markers linked to disease resistance genes by bulked segregant analysis: a rapid method to detect markers in specific genomic regions using segregating populations. Proceedings of the National Academy of Sciences of the United States of America, v.88, p.9828-9832, 1991.

OLIVEIRA, R.P. de; CRISTOFANI, M.; MACHADO, M.A. Genetic linkage maps of "Pêra" sweet orange and "Cravo" mandarin with RAPD markers. Pequisa Agropecuária Brasileira, v.39, p.159-165, 2004.

PEREIRA, H.S.; SANTOS, J.B. dos; ABREU, Â. de F.B.; COUTO, K.R. Informações fenotípicas e marcadores microssatélites de QTL na escolha de populações segregantes de feijoeiro. Pesquisa Agropecuária Brasileira, v.42, p.707-713, 2007.

PEREIRA, H.S.; SANTOS, J.B. dos; SOUZA, T.P. de; LIMA, I.A. Seleção fenotípica e assistida por marcadores moleculares de famílias de feijoeiro-comum com alta produtividade. Pesquisa Agropecuária Brasileira, v.43, p.1551-1558, 2008.

RAMALHO, M.A.P.; SANTOS, J.B. dos; PINTO, C.A.B.P. Genética na agropecuária. 4.ed. Lavras: UFLA, 2008. 472p.

RUIZ, C.; ASINS, M.J. Comparison between Poncirus and Citrus genetic linkage maps. Theoretical and Applied Genetics, v.106, p.826-836, 2003.

SARTORI, M.R. Armazenamento. In: ARAUJO, R.S.; AGUSTÍN RAVA, C.; STONE, L.F.; ZIMMERMANN, M.J. de O. (Coord.). Cultura do feijoeiro comum no Brasil. Piracicaba: Potafos, 1996. p.543-562.
SARTORI, M.R. Technological quality of dry beans (Phaseolus vulgaris $\mathrm{L}$.) stored under nitrogen. 1982. 92p. Dissertation (PhD) - Kansas State University, Manhattan.

SILVA, G.S. da; RAMALHO, M.A.P.; ABREU, A. de F.B.; SILVA, F.B. Genetic control of early grain darkening of carioca common bean. Crop Breeding and Applied Biotechnology, v.8, p.299-304, 2008.

TANKSLEY, S.D.; GANAL, M.W.; PRINCE, J.P.; DE VICENTE, M.C.; BONIERBALE, M.W.; BROUN, P.; FULTON, T.M.; GIOVANNONI, J.J.; GRANDULLO, S.; MARTIN, G.B.; MESSEGUER, R.; MILLER, J.C.; MILLER, L.; PATERSON, A.H.; PINEDA, O.; RODER, M.S.; WING, R.A.; WU, W.; YOUNG, N.D. High density molecular linkage maps of the tomato and potato genomes. Genetics, v.132, p.1141-1160, 1992.

TEIXEIRA, F.F.; SANTOS, J.B. dos; RAMALHO, M.A.P.; ABREU,A. de F.B.; GUIMARÃES, C.T.; OLIVEIRA, A.C. de.QTL mapping for angular leaf spot in common bean using microsatellite markers. Crop Breeding and Applied Biotechnology, v.5, p.272-278, 2005.

THOQUET, P.; GHÉRARDI, M.; JOURNET, E.-P.; KERESZT, A.; ANÉ, J.M.; PROSPERI, T.; HUGUET, J.M. The molecular genetic linkage map of the model legume Medicago truncatula: an essential tool for comparative legume genomics and the isolation of agronomically important genes. BMC Plant Biology, v.2, p.1-13, 2002.

TORGA, P.P.; SANTOS, J.B. dos; PEREIRA, H.S.; FERREIRA, D.F.; LEITE, M.E. Seleção de famílias de feijoeiro baseada na produtividade, no tipo de grãos e informações de QTLs. Ciência e Agrotecnologia, v.34, p.95-100, 2010.

XU, S. Quantitative trait locus mapping can benefit from segregation distortion. Genetics, v.180, p.2201-2208, 2008.

Recebido em 6 de julho de 2010 e aprovado em 4 de outubro de 2010 